\title{
Ultrasonic Biotelemetry of Muscle Activity from Free- Ranging Marine Animals: A New Method for Studying Foraging by Blue Crabs (Callinectes sapidus)
}

\author{
THOMAS G. WOLCOTT ${ }^{1}$ AND ANSON H. HINES ${ }^{2}$ \\ ${ }^{1}$ Department of Marine, Earth, and Atmospheric Sciences, North Carolina State University, \\ Raleigh, North Carolina 27695-8208, and ${ }^{2}$ Smithsonian Environmental Research Center, \\ P. O. Box 28, Edgewater, Maryland 21037
}

\begin{abstract}
The design and utilization of a small ( $16 \mathrm{~g}$ in air, $6 \mathrm{~g}$ in water) ultrasonic transmitter for animal tracking and bio-telemetry of muscle activity are described. To our knowledge this is the first use of such devices to telemeter a specific behavior (ingestion) from a free-ranging marine predator. The transmitter produces regularly recurring short tracking pulses, and long pulses triggered by the action potentials of a muscle. Pulses are transmitted through conductive estuarine water by a piezoelectric ring transducer at a frequency of about $75 \mathrm{KHz}$. The preparation of a subject animal, insertion of electrodes, and attachment of the transmitter are described for the telemetry of mandibular muscle contraction in the blue crab. The transmitter provides a signal that corresponds unequivocally with feeding activity and allows enumeration of bites required to consume a food item. Number of bites, and feeding time, are both positively correlated with the size of the prey specimen. As a test of the technique's feasibility, a blue crab was equipped with one of the transmitters and released in a subestuary of Chesapeake Bay. The crab was tracked continuously for 96 hours while every contraction of the mandibular muscle was recorded. The crab traveled $4000 \mathrm{~m}$ along the subestuary at an average speed of $12 \mathrm{~m} / \mathrm{h}$, but showed periods of rapid movement of up to $325 \mathrm{~m} / \mathrm{h}$. The crab fed 2-7 times per day, with a feeding bout comprising 15-2750 bites. The limited data did not indicate that either movement or feeding exhibit a diel or tidal cycle.
\end{abstract}

\section{Introduction}

We describe the design of a new ultrasonic telemetry transmitter for relatively small marine or estuarine ani-

Received 22 August 1988; accepted 16 November 1988 mals. In addition to producing a locating signal, it transmits a signal triggered by myopotentials occurring during muscle contraction. Thus, if activity of a muscle can be linked to a specific behavior, the transmitter can be used to obtain detailed records of that behavior from animals that cannot be directly observed. We use this device to telemeter contraction of the mandibular muscle of blue crabs (Callinectes sapidus) ranging freely in a subestuary of the Chesapeake Bay. Here we provide preliminary data on foraging activity, principally obtained from the first few crabs on which the method was tested. Subsequent papers will present the results of large-scale studies which have followed.

Ultrasonic tracking is a well-established tool in freshwater ecosystems, and is usually the only practical transmission mode in marine and estuarine waters which, being conductive, rapidly absorb radio transmissions. [Use of electromagnetic radiation in seawater is limited to very low frequencies and short distances, e.g., Phillips $e t$ al.'s (1984) system for studying the movements of rock lobsters (Panulirus cygnus) near shore.]

Ultrasonic transmission has been used primarily to track a wide variety of fish, as well as cetaceans, pinnipeds, turtles, sea snakes, and alligators (Stasko, 1975; Stasko and Pincock, 1977). Several species of invertebrates also have been tracked with ultrasonic telemetry, including queen conchs (Strombus gigas) (Clifton et al., 1970), American lobsters (Homarus americanus) (Lund and Lockwood, 1970), king crabs (Paralithodes kamtschatica) (Monan and Thorn, 1973), Norway lobsters (Nephrops norvegicus) (Chapman et al., 1975), prawns (Macrobrachium rosenbergii) (Peebles, 1978), a portunid crab (Scylla serrata) (Hill, 1978), and spiny lob- 
sters (Panulirus argus) (summarized in Herrnkind, 1980). All of these studies provided data on movements of free-ranging animals, from which behavioral information (e.g., habitat utilization) could be derived.

Ultrasonic telemetry can be used to provide directly more detailed behavioral information, in addition to location. Data on water temperature, depth, or swimming speed or direction have been telemetered from various vertebrates, providing such information as dive profiles and thermal preferences (e.g., Nelson, 1978; Westerberg, 1984; Rubinoff et al., 1986; review by Wilson et al., 1986). In some studies, ultrasonic biotelemetry has been used to record physiological functions of free-ranging animals, particularly heart rate in large vertebrates (e.g., Wardle and Kanwisher, 1974).

Bottoms and Marlow (1979) described the design of a small ultrasonic tag that uses changes in electrical impedance between two electrodes to transmit activity of a moving part, e.g., heart rate or scaphognathite beat. However, their tag was only tested successfully in the laboratory, providing preliminary data for heartbeat in a crab (Cancer pagurus). Because their method uses continuous transmission, it requires large battery capacity and is not suitable for long-term monitoring of small animals in the field. Therefore we elected to telemeter behavioral data by pulse encoding, keeping the duty cycle of power-hungry output stages, and hence the size of the battery needed, to a minimum.

Blue crabs were chosen as the study animal in developing this system for several reasons. First, the crabs are dominant benthic predators regulating the abundance and species composition of epi- and infaunal communities in oyster bars, beds of submerged vegetation, and soft bottom habitats throughout much of their range (from Cape Cod to Brazil) (Virnstein, 1976; Holland et al., 1980; Laughlin, 1982; Hines et al., in prep.). Second, because this species forms the basis of a major commercial and recreational fishery along the east and Gulf coasts of North America, there is an extensive data base on its physiology and ecology (Millikin and Williams, 1984). Finally, we wished to develop a transmitter and technique of wide applicability. A system sufficiently sensitive, small, and robust to be used on estuarine blue crabs ( $15 \mathrm{~cm}$ carapace width) would also be suitable for a variety of other estuarine and marine species.

\section{Materials and Methods}

The ultrasonic transmitter (Fig. 1) produces regularly recurring tracking pulses, and long pulses triggered by the amplified action potentials of a muscle and lasting for the duration of the contraction. The pulses are radiated from a piezoelectric cylinder and transmitted through water as high-frequency (about $75 \mathrm{kHz}$ ) sound.

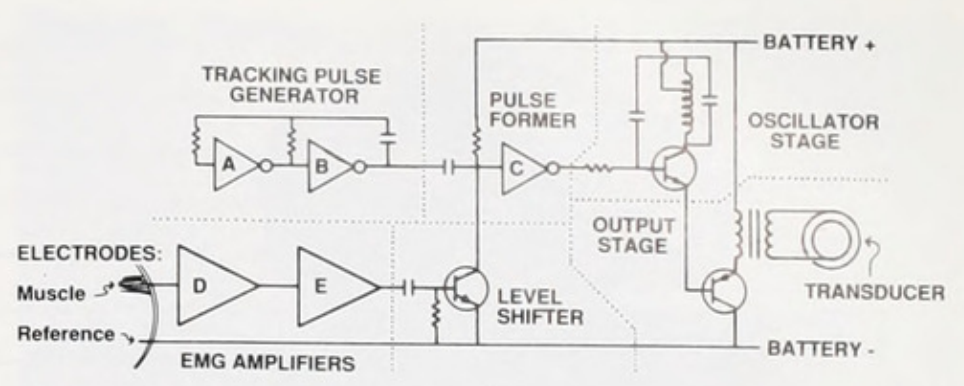

Figure 1. Schematic diagram of the telemetry transmitter. The triangles in the astable multivibrator (A, B) and pulse former $(\mathrm{C})$ represent subunits of a CMOS logic circuit (4049 hex inverter). The EMG amplifiers (D, E) are MC1776 op amps configured as non-inverting amplifiers with ac voltage gains of 100 .

Technical details of the electronic design are presented in Wolcott and Hines (1989), and detailed schematics and component lists are available from the first author; only a brief functional description of the circuit is given here.

The amplitude of the useable signal from the muscle of interest, the mandible closer, was estimated to be a few hundred microvolts. To determine the amount of voltage gain needed to switch the timing circuitry, prototype amplifiers were constructed with micro-power integrated operational amplifiers, and tested by connecting them to long wires from electrodes implanted in a crab (see below) in an aquarium. (A similar determination would have to be made each time the device is adapted to a different system). Two op-amp gain stages, amplifying the biopotentials a nominal 10,000 times, proved adequate when followed by a single-transistor amplifier that shifted the signal to logic levels. The logic level output serves as an input to the CMOS integrated circuit used for all timing of pulse signals.

The timing section of the circuit, an astable multivibrator and pulse former, produces a regular, $15 \mathrm{~ms}$ long "tracking pulse" at about $1 \mathrm{~s}$ intervals. A train of action potentials from a muscle forces the pulse former into the "on" state, producing a long, nearly continuous burst superimposed on the tracking pulses (see below). When "on," the timing circuit turns on a low power ultrasonic oscillator, which in turn drives a higher power output stage connected via a matching transformer to the piezoelectric ring transducer. The latter converts the $75 \mathrm{kHz}$ electrical signal to acoustic (ultrasonic) vibration.

The transmitter was reduced to a printed circuit and assembled using surface-mount components. A lithium battery (CR-1/3-N, $160 \mathrm{mAh}, 3 \mathrm{~g})$, powered the transmitter for more than 2 months. Completed transmitters were encapsulated originally by coating with melted vinyl-modified paraffin wax (KK731, U. S. Wax). To reduce labor, later units were inserted into vinyl electrical sleeving (Alpha PVC-80-5/8"), the ends glued shut, and 


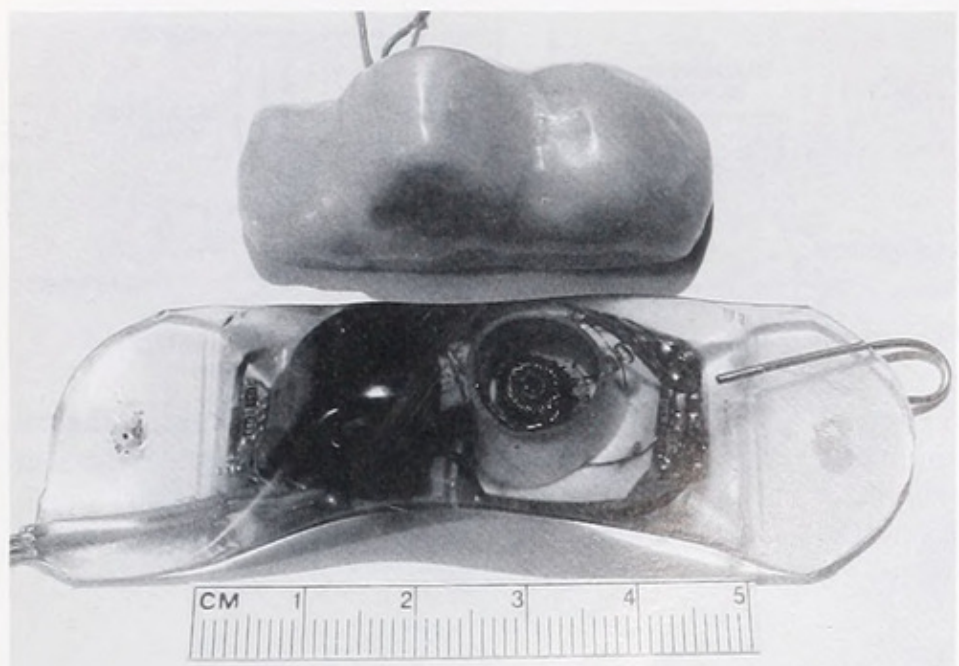

Figure 2. Completed transmitters. Above: encapsulated with wax. Below: encapsulated in vinyl sleeving. Hooked wire at right plugs the oil-fill hole.

the package backfilled with mineral oil until all air bubbles were eliminated (Fig. 2).

After some practice, we could prepare a crab, insert the electrodes, and attach the transmitter to the crab in about $20 \mathrm{~min}$. We determined by dissections that, in the blue crab, the muscles that close the mandibles originate on the front of the exoskeleton, ventro-lateral to the eye sockets (Fig. 3), where electrodes could be inserted conveniently into the end of the muscle and immobilized by fastening to the exoskeleton. Reference electrodes were sited about $1 \mathrm{~cm}$ laterally to enter the hemocoel away from any potentially interfering muscles. The surface of the exoskeleton at the electrode sites was cleaned and dried by swabbing with acetone. Using a small balltipped dental bit (no. 1/2), holes were drilled nearly through the calcified layer of the exoskeleton at the desired locations, with care not to drill completely through the exoskeleton. A patch of thin rubber (e.g., heavy dental dam) was glued to the area using a high-performance cyanoacrylate glue (Dexter Hysol 2-C-500) to provide a septum through which electrodes could be inserted without loss of blood. (Bleeding interferes with glue bonding in addition to causing undesirable physiological effects.)

Electrodes were fabricated of number 0 stainless steel insect pins cut into $1 \mathrm{~cm}$ lengths. The electrodes were bent so that they penetrated about $3 \mathrm{~mm}$ inside the exoskeleton. The active (muscle) electrode was angled to lie parallel to the muscle fibers when the outside portion was cemented flat to the exoskeleton. The reference electrode was bent about 90 degrees to enter the hemocoel perpendicular to the skeletal surface. The distal ends of the stainless steel electrodes were solder-tinned using phosphoric acid flux, thoroughly rinsed with tap water, and soldered to the transmitter's flexible leads of PVC-insulated no. 36 stranded copper wire. The electrode tips were then pushed through the rubber septum and the predrilled holes in the exoskeleton. The electrodes were immobilized and waterproofed by gluing a second layer of rubber over the entire area (Fig. 3).

The body of the transmitter, if wax-coated, was affixed to the crab with strips of thin rubber stretched over the tag and glued to the carapace. Transmitters encapsulated in vinyl sleeving were tied on with wire passed through holes at each end of the package and passed around the blue crab's large lateral spines (Fig. 3). Crabs were always placed in a large aquarium after tagging, to verify electrode placement and transmitter operation. Their behavior was observed until they fed and transmitted appropriate signals.

\section{Results}

Crabs appeared to adapt readily to carrying the transmitters. Instrumented intermolt crabs were held in the laboratory for as long as two months with no apparent ill effects, or tracked in the field for up to three weeks before being lost. Transmitters and attachments weighed about $15 \mathrm{~g}$ in air and $5.5 \mathrm{~g}$ in water when coated with wax, or $16 \mathrm{~g}$ and $6 \mathrm{~g}$, respectively, when encapsulated in oil-filled vinyl. The weight in air is about $7.5 \%$ that of a $150 \mathrm{~mm}$ carapace width (point-to-point), intermolt blue crab. In water, the transmitters probably contribute drag and

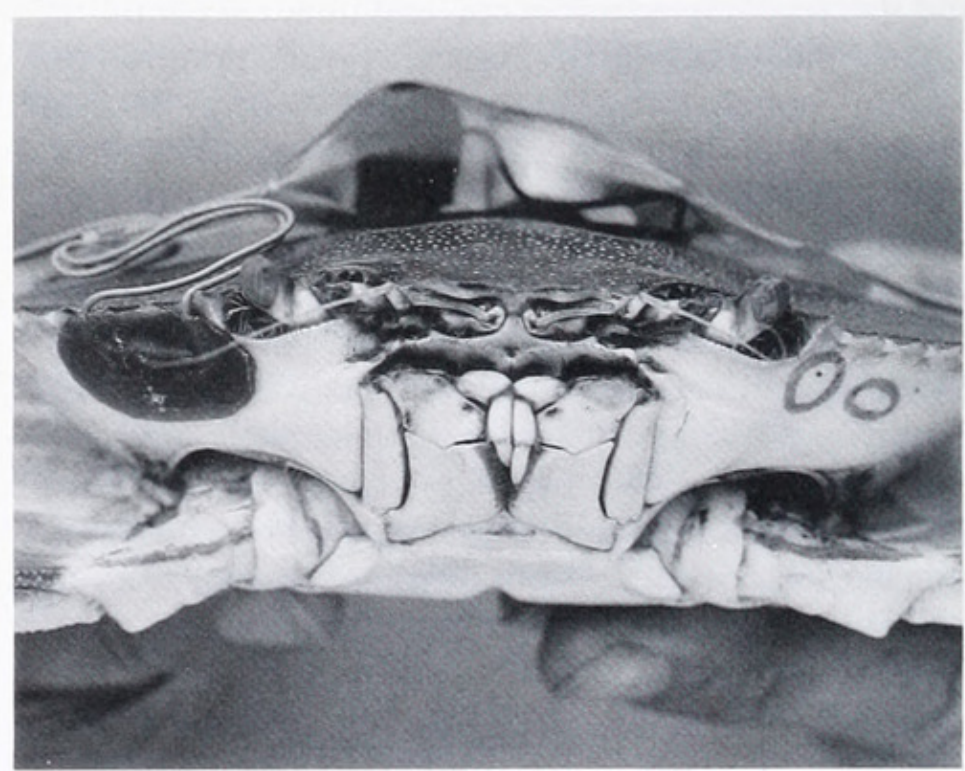

Figure 3. Crab fitted with transmitter, showing locations and typical electrode insertion. Right side of photograph: outlines on crab's "face" delineate origins of the mandible muscle. Predrilled hole for the active electrode is visible within the outline of the medial muscle origin; that for the reference electrode is lateral to the outer muscle origin. Left side of photograph: electrodes, inserted through rubber patch applied over predrilled holes, and sealed with a second rubber patch. 
Tracking Pulses
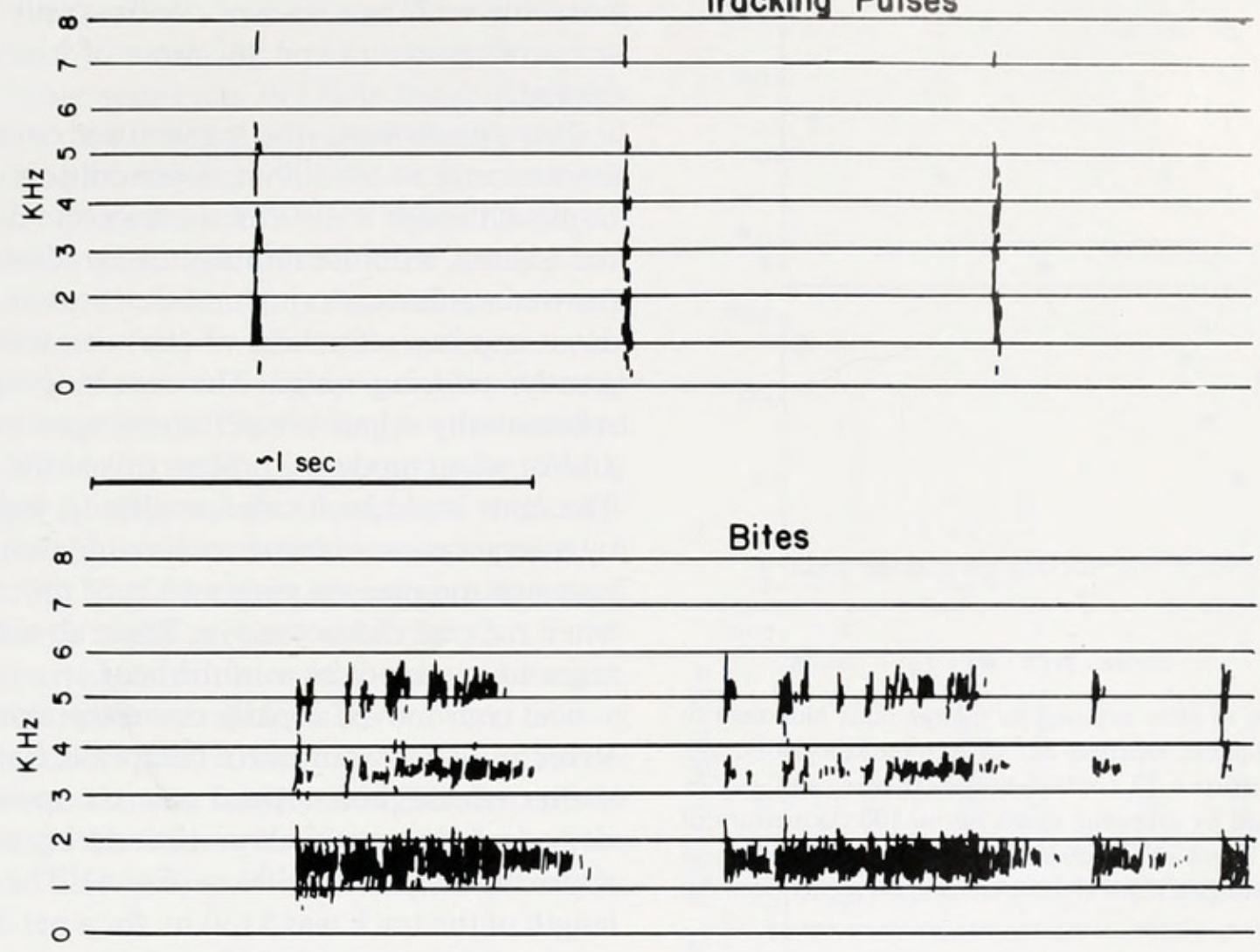

$\mathrm{TIME} \longrightarrow$

Figure 4. Sonographic representation of ultrasonic receiver output heard by operator. Top: tracking pulses (short "beeps"). Bottom: feeding signals (long "screeches"). Record shows two "bites."

weight loads similar to those caused by the barnacles sometimes found fouling crabs' carapaces. Despite the additional drag and weight, the only effect of a transmitter on a crab's behavior we could detect during careful comparative observations, of either the same crabs before and after tagging or between tagged and untagged crabs in laboratory aquaria, was an occasional attempt to preen or scrape the transmitter off. Tagged crabs otherwise exhibited normal behavior during all activities in the laboratory, including walking, swimming, digging, burying, and feeding. Moreover, when one large male released in the field ceased to feed, we retrieved him to discover that he was carrying a female in a precopulatory embrace, indicating that transmitters do not seriously interfere with sexual activity. With reasonable care in cleaning electrodes and electrode sites, no evidence of infection or serious irritation was evident. Transmitters would, of course, be cast off at ecdysis. One molt in the laboratory showed that the soft crab could withdraw from the electrodes with minimal damage, but had great difficulty in escaping from the old exoskeleton because the rubber patch prevented the dorsal carapace from lifting normally.

Laboratory observations of crabs equipped with transmitters verified that contraction of the mandibular mus- cle produced a signal distinct from the regular locating signal (Fig. 4). On the usual heterodyne-type (single conversion) ultrasonic receiver (e.g., Sonotronics USR-5), the locating signal sounds like a short "beep," whereas the muscle contraction produces a more prolonged "screech." Only contractions of the mandibular muscle consistently produced a signal; even a major startle response produced, at most, a short "beep." No other behavior, neither escape responses, vigorous aggressive behavior, nor the frequent activity of the maxillipeds, produced spurious signals.

The theoretical threshold for biopotentials to trigger output pulses was calculated to be $60-80 \mu \mathrm{V}$. However, the programmable operational amplifiers become rather slow when operated at very low currents $(10 \mu \mathrm{A})$, and the actual thresholds are somewhat higher. Minimum amplitude is about $250 \mu \mathrm{V}$ for a $0.3 \mathrm{~ms}$ square-wave input pulse, falling to about $200 \mu \mathrm{V}$ for a $4.5 \mathrm{~ms}$ input pulse. By increasing the time constant of the first amplifier stage the threshold can be lowered to about $100 \mu \mathrm{V}$, at the risk of passing increased low-frequency noise from electrode artifacts.

In the laboratory, instrumented blue crabs gave a single contraction of their mandibular muscle at irregular intervals averaging about an hour; rarely, a second con- 


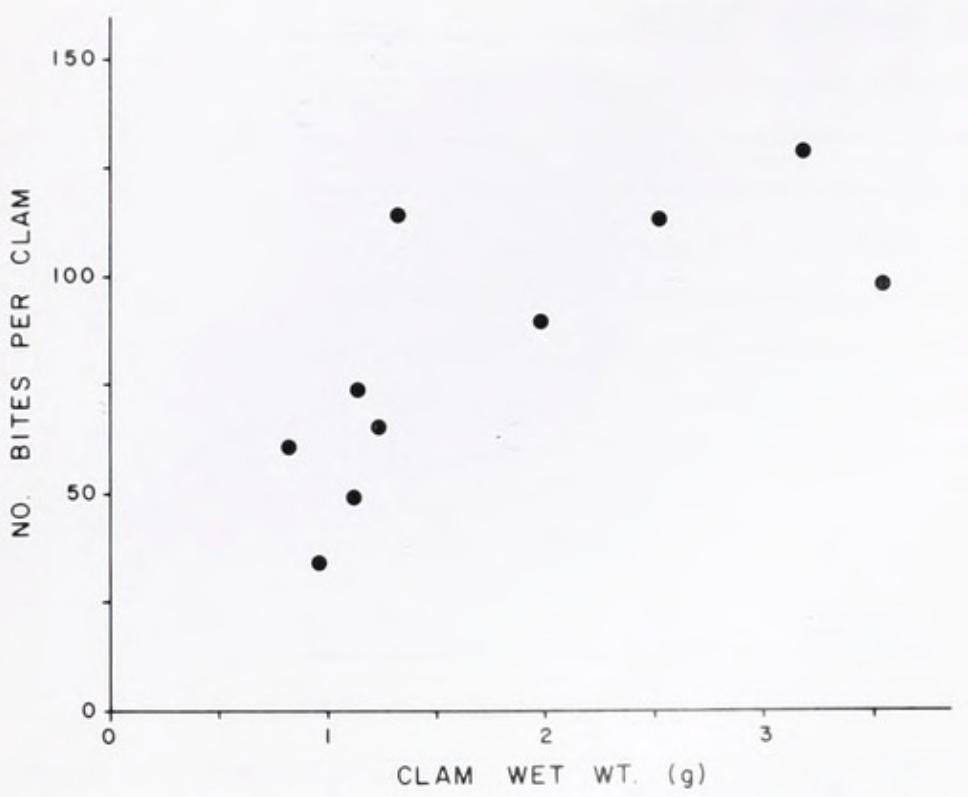

Figure 5. Number of bites required by a large male blue crab to consume prey items (clams, Macoma balthica) in the laboratory, as a function of prey size. (Bites $=22.7 \times$ Weight +42.0 ; corr coeff. $=.72$ ). Feeding was conducted by dropping clams into a 1001 aquarium of Rhode River water at about $24^{\circ} \mathrm{C}$, under subdued fluorescent light, and observing the crab through a blind while recording the signal from the transmitter

traction followed. These single (and rare double) contractions were not associated with any obvious behavior and occurred while crabs were walking or inactive, while on the sediment surface or buried. Three or more closely spaced contractions of the mandibular muscle were always associated with feeding, and the signal from each contraction was distinct enough that the number of bites during feeding could be counted. As expected, feeding clams (Macoma balthica) to the prototype instrumented crab in a laboratory aquarium showed that the number of bites required to ingest a food item was positively correlated with prey size (Fig. 5).

As a field test of the method's feasibility, a large (153 $\mathrm{mm}$ carapace width, point-to-point) intermolt male blue crab equipped with one of the ultrasonic transmitters was released on 28 July 1986 , in the Rhode River, a shallow (mean depth $=2 \mathrm{~m}$, max. depth $=4 \mathrm{~m}$ ), mesohaline subestuary of central Chesapeake Bay (see Hines et al., $1987 \mathrm{a}, \mathrm{b}$, for descriptions of the site and population biology of blue crabs in the subestuary). The crab was trapped near the head of the subestuary and immediately brought to the nearby laboratory, where it was fitted with a transmitter and electrodes for the mandibular muscle, as described above. Once fitted, the crab was held and observed in a 200-1 aquarium until it fed on a small piece of fish, confirming proper placement of the electrodes. Within $12 \mathrm{~h}$ of capture, the crab was released near its capture site. Using both directional and omni-directional hydrophones with an ultrasonic receiver in a small boat, the crab was tracked continuously for $96 \mathrm{~h}$ by a team of observers and the time of every bite was recorded.

The signals from the transmitter could be received from a range of 50-500 m, depending on weather conditions. Although a distinct thermocline did not form in the estuary, a diffuse temperature gradient developed in the water column during mid-day heat on calm summer days, causing refraction of the ultrasonic signals and greatly reducing range. The receiving range increased substantially when temperatures were cooler at night and/or when moderate breezes mixed the water column. The crab could be located readily to within one meter by triangulation with a directional hydrophone, and the boat was maintained within $10 \mathrm{~m}$ of the crab, anchoring when the crab did not move. The crab did not appear to respond to the presence of the boat.

The crab moved rapidly down the axis of the Rhode River and nearly out into Chesapeake Bay in the first 15 $\mathrm{h}$ after release, but stopped near the mouth of the river and spent the next 3 days meandering around an area approximately $200 \times 300 \mathrm{~m}$ (Fig. 6). The point-to-point length of the track was $5130 \mathrm{~m}$, for a net distance (shortest possible route) of $4213 \mathrm{~m}$ from release point to the point where tracking was terminated $96 \mathrm{~h}$ later. Average speed was $53 \mathrm{~m} / \mathrm{h}$ with speeds ranging from $0 \mathrm{~m} / \mathrm{h}$ during inactivity to $371 \mathrm{~m} / \mathrm{h}$ during directional movement,

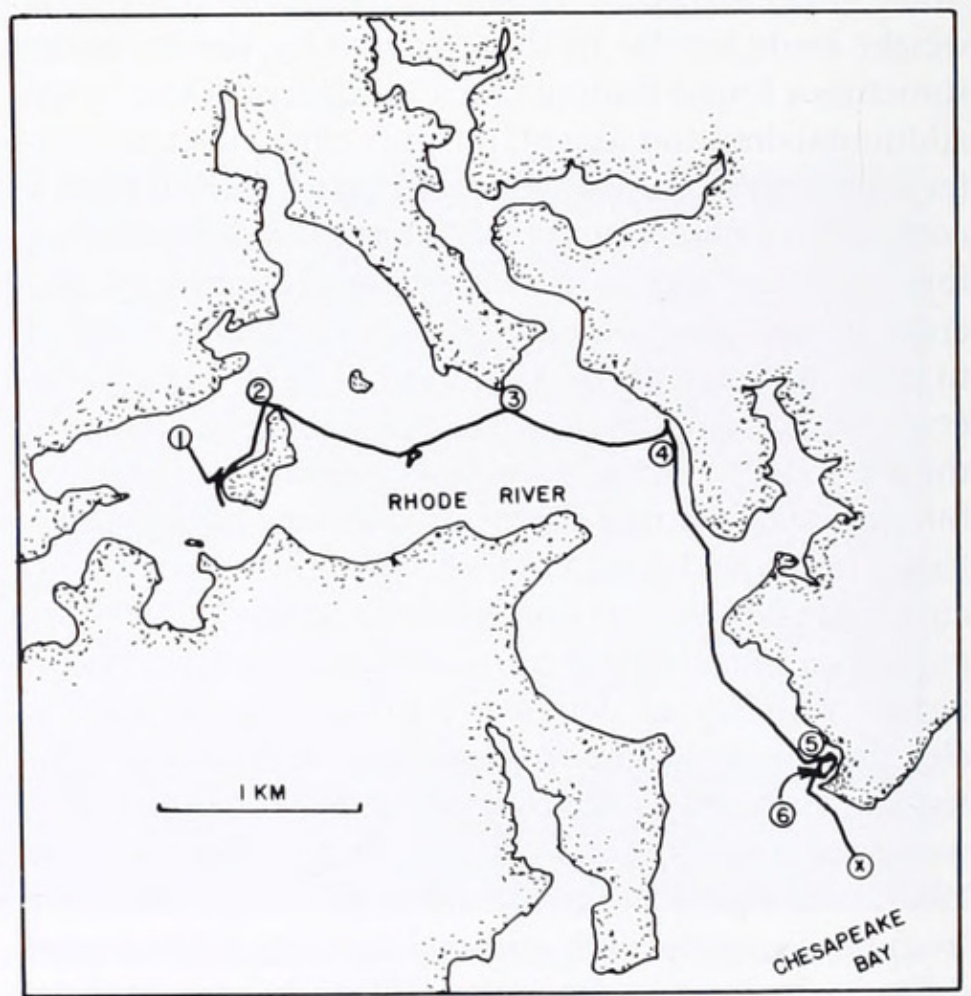

Figure 6. Track of the test blue crab in the Rhode River. Crab was released at position 1 , moved rapidly to near the river mouth (positions 2-5), and meandered in a small area (positions 5-6) for the remainder of the tracking period. It was subsequently recaptured in a crab pot at "X." 
when the crab was probably swimming. During the first $15 \mathrm{~h}$ when the crab was moving rapidly along the axis of the river, its average speed was $299 \mathrm{~m} / \mathrm{h}$; but during each of the next three days when it was meandering around near the mouth of the subestuary, its average speed was $8.6 \mathrm{~m} / \mathrm{h}$. Depths along the crab's track ranged from 0.5 $\mathrm{m}$ in sandy shallows near islands to $3 \mathrm{~m}$ on muddy bottoms of the main channel. No relationship between movement and time of day or tidal cycle was apparent.

The feeding record showed a highly variable pattern of 2-7 feeding bouts per day. The feeding bouts consisted of 15 to 2751 bites in 10 to 70 minutes and were readily apparent against a background of occasional single, apparently non-feeding muscle contractions as observed in the laboratory (Fig. 7). There were several periods lasting 10-170 minutes in which no bites were recorded. Feeding activity occurred at all times of the day and night, and there was no apparent relationship between feeding activity and the tidal cycle. Almost no feeding occurred when the crab was moving rapidly along the axis of the river, and most of the feeding bouts occurred when the crab meandered slowly around near the mouth of the subestuary.

The test crab was caught on 2 August 1986, in a commercial crab pot just outside the mouth of the subestuary, and was returned to us with the transmitter in working order.

\section{Discussion}

Although telemetry of an animal's location provides important data on movement rates, track, and habitat selection, biotelemetry of physiological function along with location can provide critical information on what animals are actually doing and how they are utilizing the habitat. Telemetry of muscular contractions provides data on the frequency, time, and location of the behavior(s) associated with a muscle's activity. The techniques we describe in this paper can be used on any muscle that is accessible for electrode implantation in an animal stout enough to carry the 5-6 g (immersed weight) telemetry package. Large arthropods are particularly well suited for this because many of their muscles originate on exposed exoskeleton, making insertion and immobilization of electrodes relatively easy. The specificity of the behavioral information derived from the telemetry will depend on the degree of specialization of the muscle's function. The techniques presented in this paper have allowed us for the first time to measure directly feeding activity of a free-ranging marine animal, by telemetering contractions of mandibular muscles.

Although the size of this transmitter and its simple electrodes will prevent its use on very small animals or very small muscles, it should be suitable for telemetering

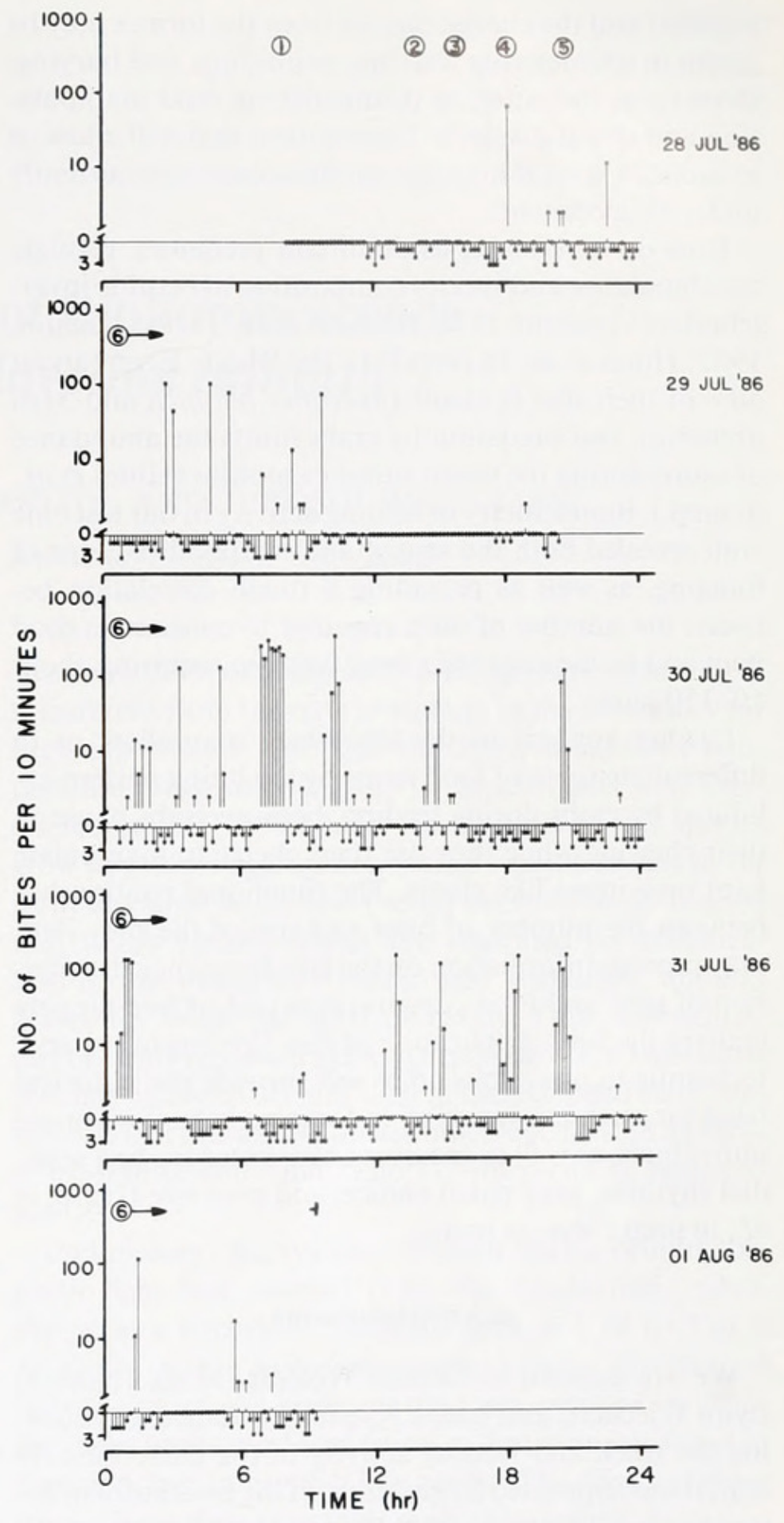

Figure 7. Four-day feeding record of the crab along the track shown in Figure 6. Circled numbers correspond to the numbered positions along the track. Lines extending upward from the axis show feeding; note that the number of bites is presented on a log scale. Isolated lines may be equated with feeding bouts. Grouped lines represent 1 or more bouts, lumped by the 10-min integrating period in this figure but resolvable in the original data. Lines below the axis represent the number of single (non-feeding) "bites" in each 10-min interval.

valuable behavioral information from a large number of decapod crustaceans (e.g., tail flips or antennal movements in lobsters). We have successfully tested the transmitter in the laboratory on other muscles in the blue crab, including those of the fifth pereiopods (swimming 
paddles) and the chelae. Signals from the former may be useful in telemetering walking, swimming, and burying; those from the latter, in distinguishing food manipulation and threat displays. Transmitters that will allow us to monitor several muscles simultaneously are currently under development.

How do blue crabs, as dominant predators, regulate the abundance and species composition of benthic invertebrates (Virnstein, 1976; Holland et al., 1979; Laughlin, 1982; Hines et al., in prep.)? In the Rhode River, about $50 \%$ of their diet is clams (Macoma balthica and Mya arenaria), and predation by crabs limits the abundance of clams during the warm summer months (Hines et al., in prep.). Biotelemetry of feeding activity in our test blue crab revealed both the spatial and temporal patterns of foraging, as well as providing a rough correlation between the number of bites required to consume a food item and its biomass (Macoma balthica requiring about $50-150$ bites).

Further analysis in the laboratory may allow us to differentiate types of food items by the biting pattern exhibited by crabs during feeding, because crabs pause in their chewing while they use their chelae to manipulate hard prey items like clams. The functional relationship between the number of bites and size of the prey item may provide information on the size-frequency distribution of prey and food consumption rate of free-ranging crabs in the field. Application of this "feeding telemetry" technique to numerous crabs will provide the statistical basis for assessing variation in foraging behavior among individuals, as well as measures of average feeding rates, diel rhythms, prey patch choice, and prey size (Hines et al., in prep.; Nye, in prep.).

\section{Acknowledgments}

We are grateful to Donna Wolcott, Mark Haddon, Lynn Wiechert, and Laura Nye for assistance in recording the track and feeding activity of the crab. This research was supported by grants from the Smithsonian Institution's Scholarly Studies Program and Environmental Science Program, and intramural funds from NC State University.

\section{Literature Cited}

Bottoms, A., and J. Marlow. 1979. A new ultrasonic tag for the telemetry of physiological functions from aquatic animals. Mar. Biol. 50: $127-130$.

Chapman, C. J., A. F. Johnstone, and A. L. Rice. 1975. The behavior and ecology of the Norway lobster, Nephrops norvegicus (L.). Proc. European Mar. Biol. Symp. 9: 54-74

Clifton, H. E., C. V. W. Mahnken, J. C. Van der Walker, and R. A. Waller. 1970. Tektite 1, Man-in-the-sea project: marine science program. Science 168: 659-663.

Herrnkind, W. F. 1980. Spiny lobsters: patterns of movement. Pp. 349-408 in The Biology and Management of Lobsters, J. S. Cobb and B. F. Phillips, eds. Vol. 1, Physiology and Behavior. Academic Press, NY.

Hill, B. J. 1976. Activity, track and speed of movement of the crab Scylla serrata in an estuary. Mar. Biol. 47: 135-141.

Hines, A. H., P. J. Haddon, J. J. Miklas, L. A. Wiechert, and A. M. Haddon. 1987a. Estuarine invertebrates and fish: sampling design and constraints for long-term measurements of population dynamics. Pp. 140-160 in New Approaches to Monitoring in Aquatic Ecosystems, T. P. Boyle, ed. ASTM STP 940, American Society for Testing and Materials, Philadelphia.

Hines, A. H., R. N. Lipcius, and A. M. Haddon. 1987b. Population dynamics and habitat partitioning by size, sex, and molt stage of blue crabs (Callinectes sapidus) in a subestuary of central Chesapeake Bay. Mar. Ecol. Prog. Ser. 36: 55-64.

Holland, A. F., N. K. Mountford, M. H. Hiegel, K. R. Kaumeyer, and J. A. Mihursky. 1980. Influence of predation on infaunal abundance in upper Chesapeake Bay, USA. Mar. Biol'57: 221-235.

Laughlin, R. A. 1982. Feeding habits of the blue crab, Callinectes sapidus Rathbun, in the Apalachicola estuary, Florida. Bull. Mar. Sci. 32: $807-822$.

Lund, W. A., and R. C. Lockwood. 1970. Sonic tag for large decapod crustaceans. J. Fish. Res. Board Can. 27: 1147-1151.

Millikin, M. R., and A. B. Williams. 1984. Synopsis of biological data on the blue crab, Callinectes sapidus Rathbun. FAO Fisheries Synopsis No. 138, National Oceanographic and Atmospheric Administration Technical Report NMFS 1, 39 pp.

Monan, G. E., and D. L. Thorne. 1973. Sonic tags attached to Alaska king crab. Mar. Fish. Rev. U. S. 35: 18-21.

Nelson, D. R. 1978. Telemetering techniques for the study of freeranging sharks. Pp. 419-482 in Sensory Biology of Sharks, Skates and Rays, E. Hodgson and R. Mathewson, eds. U. S. Govt. Printing Office, Washington, DC

Peebles, J. B. 1978. Behavioral factors influencing movement, dispersion and mortality in Macrobrachium rosenbergii. $\mathrm{Ph} . \mathrm{D}$. dissertation, University of Hawaii. 235 pp.

Phillips, B. F., L. M. Joll, and D. C. Ramm. 1984. An electromagnetic tracking system for studying the movements of rock (spiny) lobsters. J. Exp. Mar. Biol. Ecol. 79: 9-18.

Rubinoff, I., J. B. Graham, and J. Motta. 1986. Diving of the sea snake Pelamis platurus in the Gulf of Panama. I. Diving depth and duration. Mar. Biol. 91: 181-191.

Stasko, A. B. 1975. Underwater biotelemetry, an annotated bibliography. Can. Fish. Mar. Serv. Resour. Dev. Branch Marit. Reg. Tech. Rep. Ser. MAR-T 534, $31 \mathrm{p}$.

Stasko, A. B., and D. G. Pincock. 1977. Review of underwater biotelemetry, with emphasis on ultrasonic techniques. J. Fish. Res. Board. Can. 34: 1261-1285.

Virnstein, R. W. 1977. The importance of predation by crabs and fishes on benthic infauna in Chesapeake Bay. Ecology 58: 1199 1218.

Wardle, C. S., and J. W. Kanwisher. 1974. The significance of heart rate in free swimming cod, Gadus morhua: Some observations with ultrasonic tags. Mar. Behav. Physiol. 2: 311-324.

Westerberg, H. 1984. The orientation of fish and the vertical stratification at fine- and micro-structure scales. Pp. 179-203 in Mechanisms of Migration in Fishes, J. D. McCleave, G. P. Arnold, J. J. Dodson, and W. H. Neill, eds. Plenum, New York.

Wilson, R. P., W. S. Grant, and D. C. Duffy. 1986. Recording devices on free-ranging marine animals: does measurement affect foraging performance? Ecology 67: 1091-1093.

Wolcott, T. G., and A. H. Hines. 1989. Ultrasonic telemetry transmitters for behavioral studies on free-ranging estuarine blue crabs (Callinectes sapidus). In Proc. 10th International Symposium on Biotelemetry, C. J. Amlaner Jr., ed. Univ. of Arkansas Press, Fayetteville. (In Press.) 


\section{$2 \mathrm{BHL}$ Biodiversity Heritage Library}

Wolcott, Thomas $\mathrm{G}$ and Hines, Anson H. 1989. "Ultrasonic Biotelemetry of Muscle Activity from Free-Ranging Marine Animals: A New Method for Studying Foraging by Blue Crabs (Callinectes sapidus)." The Biological bulletin 176, 50-56. https://doi.org/10.2307/1541888.

View This Item Online: https://www.biodiversitylibrary.org/item/17430

DOI: https://doi.org/10.2307/1541888

Permalink: https://www.biodiversitylibrary.org/partpdf/10942

\section{Holding Institution}

MBLWHOI Library

\section{Sponsored by}

MBLWHOI Library

\section{Copyright \& Reuse}

Copyright Status: In copyright. Digitized with the permission of the rights holder.

License: http://creativecommons.org/licenses/by-nc-sa/3.0/

Rights: https://biodiversitylibrary.org/permissions

This document was created from content at the Biodiversity Heritage Library, the world's largest open access digital library for biodiversity literature and archives. Visit BHL at https://www.biodiversitylibrary.org. 